\section{Modeling Benefit-cost Analysis of Hemlock Wooly Adelgid Host Plant Resistance with Emphasis on Least-toxic Chemical Treatment Alternatives}

\author{
Jason Ernest Elvin Dampier ${ }^{1,5}$, Richard W. Harper ${ }^{2}$, \\ Ashley McElhinney ${ }^{3}$, and Eric Biltonen ${ }^{4}$
}

Additional index words. Adelges tsugae, cost-benefit analysis, energy conservation, Tsuga canadensis, Tsuga chinensis

Summary. Chinese hemlock (Tsuga chinensis) exhibits a high level of resistance to the exotic insect hemlock woolly adelgid (HWA; Adelges tsugae) relative to the native and widely planted eastern hemlock (Tsuga canadensis). Furthermore, both chinese and eastern hemlock exhibit similar autecologic and aesthetic characteristics in urban and suburban environments. This study provides a comparative 25-year economic benefit-cost analysis (BCA), tracking estimated establishment and insect control costs for the two tree species. Eastern hemlock survival requires insecticide treatments when growing within the range of HWA. Insect control scenarios used and evaluated in this study include annual horticultural oil spray, biannual horticultural oil spray, biennial imidacloprid soil drench, and no treatment. The chinese hemlock scenario did not include chemical insect control because of the species' host plant resistance (HPR) to HWA. Benefits were estimated using the U.S. Department of Agriculture, Forest Service's i-Tree tool, which estimates economic benefits for ecosystem services (expressed in dollars). Benefit-cost ratios (BCRs) were developed using the present value for 25-year benefit and cost streams at $2 \%$ and $4 \%$ discount rates. Payback periods were also estimated for all options that had a calculated BCR greater than one. The benefit-cost analyses for each insect control scenario were evaluated, compared, and assessed through the lens of market potential. The costs exceed the benefits for all of the eastern hemlock scenarios. The benefits exceed costs for the chinese hemlock scenario. Results suggest that chinese hemlock is a viable alternative to eastern hemlock in view of its HPR and reduced associated costs over time. If chinese hemlock becomes more widely planted, it is expected to produce greater BCRs relative to chemical control options as a result of the lack of required, ongoing insect control treatment costs.

$\mathrm{H}$ emlock woolly adelgid is a tiny, sap-feeding insect originating from Asia (McClure, 1987, McClure et al., 2001). It was first confirmed in Virginia in the 1950s, likely arriving on plant material imported for a private plant collection (Havill and Montgomery, 2008). Since that time, it has been recognized as a serious pest, killing entire populations of eastern hemlock (Del Tredici and Kitajima, 2004). Currently, HWA is

${ }^{1}$ University of Wisconsin-Extension, UW Extension County Services Center, 480 Underwood Avenue, Montello, WI 53949

${ }^{2}$ Department of Environmental Conservation, University of Massachusetts, 320 Holdsworth Hall, 160 Holdsworth Way, Amherst, MA 01003

${ }^{3}$ Department of Environmental Conservation, University of Massachusetts, 160 Holdsworth Way, Amherst, MA 01003

${ }^{4}$ University of Wisconsin-Extension, 1960 8th Avenue, Suite 140, Baldwin, WI 54016

${ }^{5}$ Corresponding author. E-mail: jay.dampier@ces.uwex. edu.

https://doi.org/10.21273/HORTTECH04080-18 established in much of the eastern hemlock range (Hessl and Pederson, 2012), which includes portions of the eastern United States, north to Maine, south to Georgia, and westward. It has been conjectured that HWA poses a major threat to the long-term survival of vulnerable host species such as eastern hemlock (Foster, 2014). The insect's success is a result in part of its ability to expand its range readily via vectors such as wind, birds, and mammals. HWA's negative impact on eastern hemlock is also a result of its ability to feed year-round (McClure, 1987;
Ward et al., 2004). By withdrawing sap from young twigs, the insect impedes tree growth, causing needle discoloration (i.e., turning grayish green) and premature needle drop. The loss of new shoots and needles weakens trees critically, eventually leading to death (McClure et al., 2001). This insect is capable of killing untreated susceptible hemlock in less than a decade in horticultural settings (Harper and Weston, 2016; Hoover et al., 2009; Weston and Harper, 2009), and in some cases in less than 5 years (McClure, 1987; Radville et al., 2011). Although HWA is arguably the most important eastern hemlock pest, other insects not considered in this study may also play an important role in overall plant health, including elongate hemlock scale (Fiorinia externa).

Eastern hemlock is functionally important in horticultural settings because it tolerates shade, functions well as a screen, and withstands pruning and shearing. With eastern hemlock's potential loss as a viable horticultural planting, horticulturists will have one less shade-tolerant evergreen screen available. According to one extension horticulturist (G.G. Giordano, personal communication): "As hemlock wooly adelgid became an increasingly serious problem over the last several decades, the difficulty of suggesting a replacement that would perform the functions that eastern hemlock provides in the landscape became more and more apparent. Even available species that could partially perform some of these functions lacked the critical aesthetic found only in eastern hemlock."

Eastern hemlock's susceptibility to HWA is impacting nursery growers as well (K. MacIndoe, personal communication): "We have averaged $\$ 10,000$ in sales of [eastern] hemlock over the past 10 years. We have sold $\$ 0$ worth of [eastern] hemlocks the past 2 years."

Although new plantings of eastern hemlock are likely in decline, the

\begin{tabular}{llll}
\hline $\begin{array}{l}\text { Units } \\
\begin{array}{l}\text { To convert U.S. to SI, } \\
\text { multiply by }\end{array}\end{array}$ & U.S. unit & SI unit & $\begin{array}{l}\text { To convert SI to U.S., } \\
\text { multiply by }\end{array}$ \\
\hline 0.4047 & acre(s) & ha & 2.4711 \\
0.3048 & $\mathrm{ft}$ & $\mathrm{m}$ & 3.2808 \\
3.7854 & gal & $\mathrm{L}$ & 0.2642 \\
2.54 & inch(es) & $\mathrm{cm}$ & 0.3937 \\
25.4 & inch(es) & $\mathrm{mm}$ & 0.0394
\end{tabular}


control of HWA on susceptible hemlock species can be achieved through recurring insecticide applications (Harper and Cowles, 2013; McClure, 1987) and is usually most efficacious when insect populations are low and tree health has not been seriously compromised (Ward et al., 2004). Effective chemical HWA control includes the use of contact insecticides such as horticultural oil or systemic insecticides like imidacloprid (McClure, 1987; Webb et al., 2003). In addition to pesticide applications, eastern hemlock health can be maintained with cultural practices such as mulching to help maintain adequate soil moisture and to avoid nitrogen fertilizers that are linked to enhanced HWA survival and reproduction (McClure et al., 2001). Insecticidefree control of HWA is continuing to garner interest and involves the strategy of replacing pest-prone species with pest-resistant ones. This strategy, known as host plant resistance, or HPR, is an important strategy in agricultural and forested settings (Beck, 1965; Herms, 2002). With mounting social and regulatory pressures demanding the use of less pesticides in urban and suburban environments, HPR may offer a long-term, costeffective strategy (Herms, 2002) for the management of HWA.

Research suggests that chinese hemlock may serve as a suitable HPR replacement for eastern hemlock (Harper and Weston, 2016; Weston and Harper, 2009), especially when viewed through the lens of consumer preference (Dampier et al., 2015). However, there is a dearth of studies comparing economic benefits against the costs of establishment and of insect control required to maintain healthy hemlock species in HWA-infested areas. While building upon previous hemlock research, this work addresses the knowledge gap by providing a comparative 25-year economic benefit-cost modeling and analysis, tracking estimated purchase, establishment, and maintenance costs of the two tree species. A time horizon of 25-years was chosen as a suitable "project" duration, despite both tree species having a lifespan that greatly exceeds this period.

\section{Methods}

Growth Model. Chinese and eastern hemlock were assumed to grow at similar rates (Del Tredici and Kitajima, 2004). Although tree growth curves typically follow nonlinear functions, a straight-line relationship was assumed for both diameter and height because of the relatively short time-series. Annual growth increments were estimated by using published diameter and height growth rate data (Solomon and Leak, 1999; Teck and Hilt, 1991). In the model, we used a diameter growth rate of $0.25 \mathrm{inch} /$ year and a linear height growth rate of 12 inches/year. Initial conditions at year 0 are 0.25 -inch-diameter breast height ( 54 inches above the ground)] and 54 inches high. Growth was then modeled using annual steps for 25 years. A similar growth rate was assumed for both species because they both possess similar physiologic traits and autecologic requirements, and are closely related taxonomically.

Because this project is a component of a broader integrated study, the modeled growth was checked against actual growth data from trees at our study site located at Lasdon Park and Arboretum in Westchester County, NY. The property is $\approx 94$ ha and is owned and operated by Westchester County Department of Parks, Recreation and Conservation. Both tree species were open-grown in full sun, inside deer fencing. Both species of trees were assessed visually and given a visual health rating: 5 = excellent, 4 = good, 3 = fair, $2=$ poor, $1=$ critical, and $0=$ dead.

Cost calculations. Alternative HWA control scenarios compare the economic benefits and costs of insect control treatment options over a 25year series (Table 1). We assumed that all nursery stock planted in year 0 is in "excellent" condition. We also assumed there was no difference in planting costs for all five scenarios. Purchased planting stock for this size typically comes in standard no. 5 containers (volume, $3.8 \mathrm{gal}$ ). Estimated retail purchase prices and planting costs are expressed in U.S. dollars (2017). After the initial purchase and establishment costs were determined, recurring annual insect control treatment costs for each scenario were estimated for the 25-year period. No recurring insect control treatment costs were applied to the eastern hemlock control scenario (TCan-0) and the chinese hemlock HPR scenario (TChin$0)$. Furthermore, we assumed that the HWA-susceptible eastern hemlock scenario receiving no insect control would decline from excellent health to complete mortality by year 5 (TCan- 0 ).

In modeling plant health over time, we assumed that HWA-resistant chinese hemlock (TChin-0) maintained excellent health during the 25-year period. For the eastern hemlock treated once per year with horticultural oil in April or early May (Cornell University, 2014) (TCanOill), we assumed the tree was in excellent health in the first year and declined to good health in subsequent years. We applied the assumption that one oil treatment per year can provide effective control, but we wanted to recognize the likelihood that one oil treatment per year may be less effective than the recommended two oil treatments per year (Cornell University, 2014). For the other two scenarios involving eastern hemlock, we assumed that excellent health during the 25-year period was maintained. These two scenarios include eastern hemlock being treated twice per year with oil in April or early May, and again in mid July (TCan-Oil2), and the other treated biennially with imidacloprid (TCan-Drench) (Cornell University, 2014). All insect control treatment costs are expressed in U.S. dollars (2017) and were ascertained by collecting local market cost data from local tree-care industry professionals, and then discount rates were applied at $2 \%$ and $4 \%$ to estimate upper and lower likely thresholds.

Benefit calculations. A benefit estimate for each scenario was estimated by employing the U.S. Department of Agriculture Forest Service i-Tree MyTree calculator (i-Tree, n.d.), annually for the 25-year time series. The tool estimates the following ecosystem services expressed in U.S. dollars: 1) carbon dioxide sequestration through mitigation of climate change impacts; 2) stormwater interception and mitigation of storm damage; 3) air pollution removal (an external value from health impacts), damage to landscape and ecosystems, and reduced visibility; and 4) energy usage savings for adjacent buildings through shading, evaporative cooling, and blocking of wind.

Because fully mature hemlock in horticultural settings can spread 25 to $35 \mathrm{ft}$, and because it is not uncommon in the northeastern United States that suburban homes are built after 1980, we entered these parameters into the 


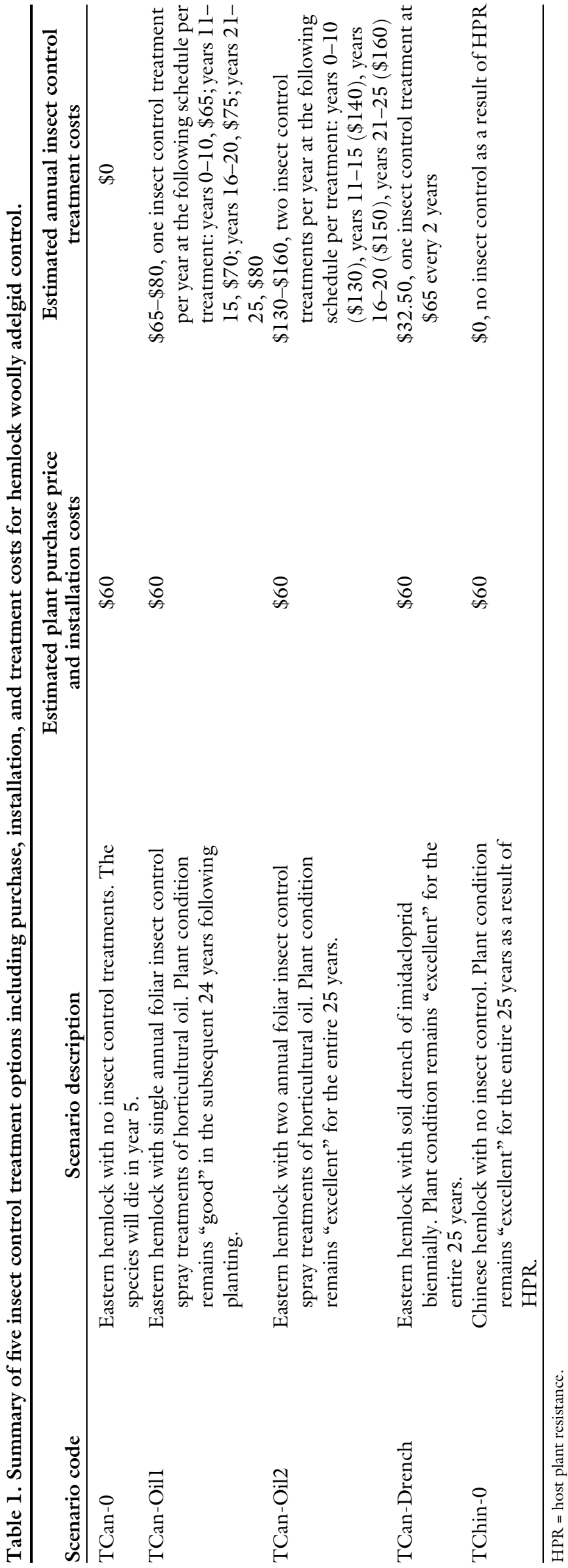

i-Tree model (i-Tree, n.d.; Markarian et al., 2016). Although the i-Tree tool estimates economic benefit valuations for a number of ecosystem services, we decided to investigate and include only energy use savings, because the other three benefits were relatively minor and their inclusion or exclusion would not impact the benefit calculations in a meaningful way.

Ratio calculations. A BCR is developed to conduct a BCA for each scenario. BCR is an analysis tool used to assess whether benefits exceed costs for a given project, indicating whether a project is viable (Boardman et al., 2018). Ratios less than one indicate costs exceed benefits and that a project is not economically feasible. Ratios greater than one indicate benefits exceed costs and a project is economically feasible. BCA is often used for comparing projects of a similar nature, such as assessing different tree species' economic performance in horticultural settings. BCR is calculated by the following equation:

$$
\mathrm{BCR}=\frac{\Sigma \frac{B}{(1+r)^{t}}}{\Sigma \frac{C}{(1+r)^{t}}}
$$

where $B$ and $C$ are benefits and costs, respectively, associated with each tree species and site over time $t$ ( 25 years), and $r$ is the discount rate. We used discount rates of $2 \%$ and $4 \%$. The decision criterion is a BCR greater than one indicates a feasible option (i.e., benefits exceed costs over the life of the project). All scenarios that had BCRs greater than one were graphed at the $2 \%$ and $4 \%$ discount rates to investigate further the relationship between benefits and costs over time, and to assess the payback period visually.

\section{Results and discussion}

For all insect control treatment scenarios (TCan-0, TCan-Oill, TCan-Oil2, and TCan-Drench), the costs exceed the benefits for eastern hemlock at both the $2 \%$ and $4 \%$ discount rates. The BCRs for insect control treatment scenarios with eastern hemlock range from 0.00 to 0.17 (Table 2). For the chinese hemlock scenario (TChin-0), benefits exceed control costs at both the $2 \%$ and $4 \%$ discount rates. The BCRs for TChin-0 scenario with chinese hemlock are 2.07 and 1.42 , respectively (Table 2 ). 
Through a human perceptions lens, chinese and eastern hemlock may be considered perfect substitutes. Perfect substitute describes consumer behavior: When a consumer is presented with two nearly identical buying options, the consumer switches readily between alternatives based on price, access, or convenience. Considering previous perceptions work on chinese and eastern hemlock, it is likely that a consumer will likely switch to the lower cost, higher BCR option (i.e., chinese hemlock) (Dampier et al., 2015). Furthermore, the option that requires less pesticide inputs will likely be desirable for consumers who are adverse to repeated pesticide applications over time. These considerations can be important selling features when introducing new plant material to market.

Because chinese hemlock BCRs are positive at both discount rates, this scenario was further analyzed. Benefits and costs reached parity (i.e., payback period) at about 20 years at the $2 \%$ discount rate (Fig. 1A) and at about 22 years at the $4 \%$ discount rate (Fig. 1B). The horizontal lines (solid) in Fig. I present the scenario's feature of no additional postinstallation insect control treatment costs resulting from the HPR of chinese hemlock. The accumulated annual energy savings benefits accrue over time, as indicated by the upward trend (dashed lines). The point of line intersection indicates the payback period.

Figure $\mathrm{l}$ indicates that the $\mathrm{i}$-Tree model increases the rate of energy savings at 14 years postplanting. As a tree increases in size, its effect on adjacent buildings' heating and cooling is expected to increase. Other factors leading to variations to energy savings include planting distance to building, cardinal location, and evergreen vs. deciduous (i.e., functioning as windbreak vs. shade tree). Even under various initial conditions, it is expected HPR options would likely result in greater BCRs relative to chemical control options over time, resulting from the lack of required ongoing insect control treatment costs.

Although the effective control of HWA on the non-HPR eastern hemlock is costly, some consumers may not view chinese and eastern hemlock as perfect substitutes and may prefer

Table 2. Benefits, costs, and benefit-cost ratio (BCR) for hemlock wooly adelgid host plant resistance and chemical insect control alternatives at $2 \%$ and $4 \%$ discount rates for a 25-year period.

\begin{tabular}{|c|c|c|c|c|c|c|}
\hline \multirow[b]{2}{*}{ Treatment scenarios } & \multicolumn{2}{|c|}{ Benefit } & \multicolumn{2}{|c|}{ Costs } & \multicolumn{2}{|c|}{ BCR } \\
\hline & $2 \%$ & $4 \%$ & $2 \%$ & $4 \%$ & $2 \%$ & $4 \%$ \\
\hline TCan-0 & $\$ 0$ & $\$ 0$ & $\$ 60$ & $\$ 60$ & 0.00 & 0.00 \\
\hline TCan-Oill & $\$ 121$ & $\$ 83$ & $\$ 1,496$ & $\$ 998$ & 0.08 & 0.08 \\
\hline TCan-Oil2 & $\$ 124$ & $\$ 85$ & $\$ 2,424$ & $\$ 1,729$ & 0.05 & 0.05 \\
\hline TCan-Drench & $\$ 124$ & $\$ 85$ & $\$ 734$ & $\$ 518$ & 0.17 & 0.16 \\
\hline TChin-0 & $\$ 124$ & $\$ 85$ & $\$ 60$ & $\$ 60$ & 2.07 & 1.42 \\
\hline
\end{tabular}

TCan- $0=$ eastern hemlock with no insect control treatments; the species will die in year 5 . TCan-Oill $=$ eastern hemlock with single annual foliar insect control spray treatments of horticultural oil; plant condition remains "good" in the subsequent 24 years following planting. TCan-Oil2 = eastern hemlock with two annual foliar insect control spray treatments of horticultural oil; plant condition remains "excellent" for the entire 25 years. TCanDrench = eastern hemlock with soil drench of imidacloprid biennially; plant condition remains "excellent" for the entire 25 -year period. TChin- 0 = chinese hemlock with no insect control; plant condition remains "excellent" for the entire 25 years as a result of host plant resistance.

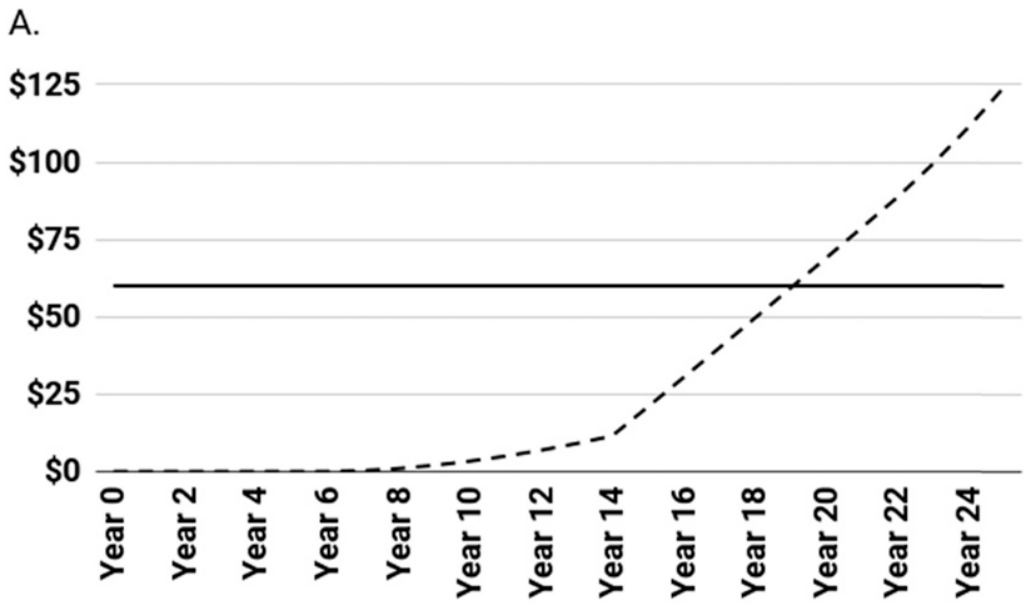

B.

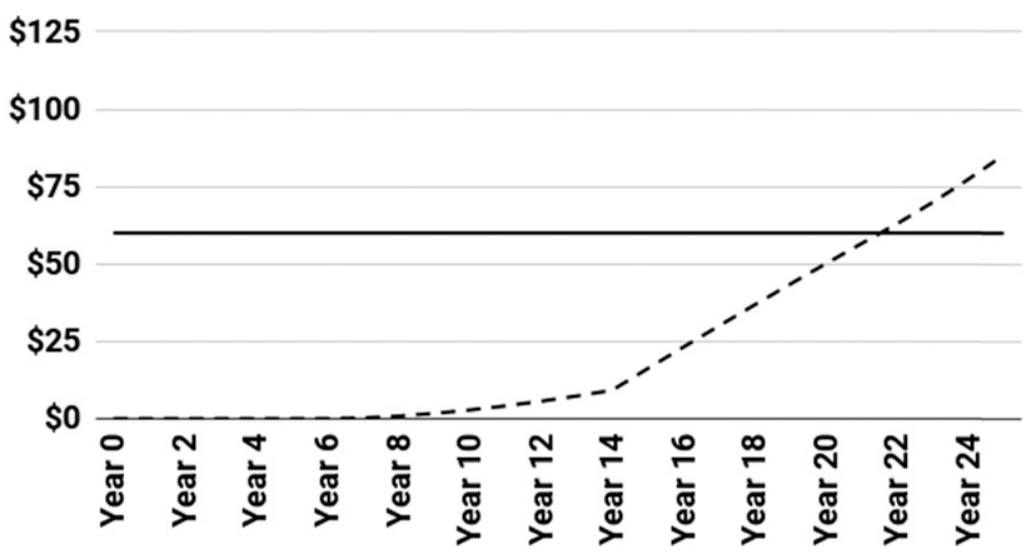

Fig. 1. Cost and benefit curves for hemlock wooly adelgid host plant-resistant chinese hemlock over a 25-year period. Cost curves are solid lines. Benefit curves are dashed lines. (A) Costs and benefits at a $2 \%$ discount rate. (B) Costs and benefits at a $4 \%$ discount rate.

the higher cost, lower BCR option (i.e., eastern hemlock). This consumer preference may be a result of the eastern hemlock's strong historical and cultural role in the northeastern United States (Foster, 2014), or perhaps this consumer preference may be the result of an aversion to nonnative tree species. Furthermore, eastern hemlock may be the only option because of market availability. Of the eastern hemlock scenarios, TCanDrench yielded the greatest BCR. If eastern hemlock is the only option available, the biennial soil drench would be the best HWA control 
option when viewed solely through the BCA.

\section{Conclusions}

Work presented in this paper builds upon previously published autecologic and human perceptions work, adding an economic dimension to the growing body of knowledge on HPR chinese hemlock. Without economic data, arboriculture and nursery practitioners are less able to evaluate chinese hemlock's attributes properly as an alternative to the HWA-susceptible eastern hemlock. The results of the BCA presented here indicate that, over a 25-year period, chinese hemlock is a strong HPR alternative to eastern hemlock. The popular chinese hemlock's HPR to HWA and associated high BCR makes chinese hemlock a strong candidate for broad introduction and replacement of eastern hemlock. Even in areas where HWA is not currently affecting landscapeplanted eastern hemlock, it may be a wise and proactive practice to plant chinese hemlock before local incursion and establishment. Further market studies could be conducted to determine markets on a broader scale.

\section{Literature cited}

Beck, S.D. 1965. Resistance of plants to insects. Annu. Rev. Entomol. 10(1):207232.

Boardman, A.E., D.H. Greenberg, A.R. Vining, and D.L. Weimer. 2018. Costbenefit analysis: Concepts and practice. 4th ed. Cambridge Univ. Press, Cambridge, UK.

Cornell University. 2014. 2014 Cornell pest management guide for commercial production and maintenance of trees and shrubs. Pesticide Mgt. Educ. Program, Cornell Univ., Ithaca, NY.

Dampier, J.E.E., R.W. Harper, L. Schwartzberg, and R.H. Lemelin. 2015.
A comparison of arborists' and horticulturists' preferences of Tsuga chinensis to $T$. canadensis in the urban landscape. Arboricult. Urban For. 4l(1):41-48.

Del Tredici, P. and A. Kitajima. 2004. Finding a replacement for the eastern hemlock: Research at the Arnold Arboretum. Arnoldia 63(2):33-39.

Foster, D.R. (ed.). 2014. Hemlock: A forest giant on the edge. 1st ed. Yale Univ. Press, New Haven, CT.

Harper, R.W. and R.S. Cowles. 2013. Susceptibility of chinese hemlock (Tsuga chinensis) to injury from autumn horticultural oil applications. Arboricult. Urban For. 39(1):6-10.

Harper, R.W. and P.A. Weston. 2016. Potential of alternative Tsuga spp. as landscape replacements from western North America and Asia as replacements for T. canadensis: Longer-term evaluation and propagation of T. canadensis. Arboricult. Urban For. 42(5):346-354.

Havill, N.P. and M.E. Montgomery. 2008. The role of arboreta in studying the evolution of host resistance to the hemlock woolly adelgid. Arnoldia 65(3):2-9.

Herms, D.A. 2002. Strategies for deployment of insect resistant ornamental plants, p. 217-235. In: M.R. Wagner, K. M. Clancy, F. Lieutier, and T.D. Paine (eds.). Mechanisms and deployment of resistance in trees to insects. Kluwer Acad. Publ., Dordrecht, The Netherlands.

Hessl, A. and N. Pederson. 2012. Hemlock Legacy Project (HeLP): A paleoecological requiem for eastern hemlock. Prog. Phys. Geogr. 37(1):114-129.

Hoover, B.K., R.M. Bates, J.C. Sellmer, and G.A. Hoover. 2009. Challenging chinese hemlock (Tsuga chinensis) with hemlock woolly adelgid (Adelges tsugae) ovisacs. Arboricult. Urban For. 35(1):1-4.

i-Tree. n.d. i-Tree software suite vl.2. 2 Feb. 2018. <https://mytree.itreetools. $\operatorname{org} />$.
Markarian, G., R.W. Harper, and D.V. Bloniarz. 2016. Flexible, open-source programmes and estimating projections of urban tree benefits: A case study in Amherst, MA. Arboric. J. 38(1):1-13.

McClure, M.S. 1987. Biology and control of hemlock wooly adelgid. Connecticut Agr. Expt. Sta., New Haven, CT.

McClure, M.S., S.M. Salom, and K.S. Shields. 2001. Hemlock wooly adelgid. FHTET-2001-03. U.S. Dept. Agr., For. Serv., Morgantown, WV.

Radville, L., A. Chaves, and E.L. Preisser. 2011. Variation in plant defense against invasive herbivores: Evidence for a hypersensitive response in eastern hemlocks (Tsuga canadensis). J. Chem. Ecol. 37(6): 592-597.

Solomon, D.S. and W.B. Leak. 1999. Growth and stocking of eastern hemlock (Tsuga. canadensis) in New England, p. 43-49. In: K.A. McManus, K.S. Shields, and D.R. Souto. (eds.). Proc. Symp. Sustainable Mgt. Hemlock Ecosystems Eastern North America. U.S. Dept. Agr., For. Serv., Newtown Square, PA.

Teck, R.M. and D.E. Hilt. 1991. Individual tree-diameter growth model for the northeastern United States. NE-649. U.S. Dept. Agr., For. Serv., Radnor, PA.

Ward, J.S., M.E. Montgomery, C.A.S.-J. Cheah, B.P. Onken, and R.S. Cowles. 2004. Eastern hemlock forests: Guidelines to minimize the impacts of hemlock woolly adelgid. NA-TP-03-04. U.S. Dept. Agr., For. Serv., Morgantown, WV.

Webb, R.E., J.R. Frank, and M.J. Raupp. 2003. Eastern hemlock recovery from hemlock wooly adelgid damage following imidacloprid therapy. J. Arboric. 29(5):298-302.

Weston, P.A. and R.W. Harper. 2009. Potential of Tsuga spp. from western North America and Asia as replacements for eastern hemlock (Tsuga canadensis). Arboricult. Urban For. 35(1):5-9. 